\title{
Povos tradicionais e manejo de recursos naturais: valores socioambientais das comunidades ao entorno da Reserva Estadual de Desenvolvimento Sustentável Veredas do Acari - Minas Gerais/Brasil
}

\author{
Pueblos tradicionales y gestión de recursos naturales: los valores sociales \\ y ambientales de las comunidades alrededor de la Reserva del Estado para \\ vías de desarrollo sostenible de Acari-Minas Gerais/Brasil
}

Traditional peoples and natural resource management: socioenvironmental values of the communities surrounding the State Sustainable Development Reserve Veredas do Acari - Minas Gerais / Brazil

Nadja Maria Mourão ${ }^{1}$

Rita de Castro Engler ${ }^{2}$

Rosilene Conceição Maciel $^{3}$

\begin{abstract}
Resumo
Este trabalho busca investigar os aspectos dos povos tradicionais e manejo dos recursos naturais, em função dos valores socioambientais, das comunidades ao entorno da Reserva Estadual de Desenvolvimento Sustentável Veredas do Acari, em função do artesanato. Para tanto, utiliza-se a metodologia da pesquisa-ação, por meio da realização de oficina de Design, Identidade e Cultura. Acredita-se que o design social pode contribuir com o desenvolvimento sustentável na região. A Reserva Ambiental do Acari garante a subsistência e área de vegetação, que são recursos, para as comunidades próximas à região. A comunidade deve ser orientada sobre os métodos adequados para a extração de materiais e sobre como evitar incêndios, valorizando a biodiversidade local. Em visitas técnicas, foram identificados alguns costumes relacionados com as tradições e atividades culturais. Observaram-se quais os conhecimentos de produção artesanal e conceitos sociais, culturais e ambientais, que configuram em vínculo com a produção artesanal. O material didático, para execução de oficinas, foi preparado com a participação das lideranças comunitárias. Verificou-se a compatibilidade com a realidade local, oferecendo conteúdos que pudessem auxiliar no desenvolvimento dos produtos artesanais. As atividades de reconhecimento das riquezas materiais e imateriais, desenvolvidas durante as oficinas de design, estimularam a valorização do contexto histórico e das tradições locais. Foram executadas análises sobre as
\end{abstract}

\footnotetext{
${ }^{1}$ Mestra em Design pela ED-UEMG; Doutoranda em Design; Centro de Estudos em Design e Tecnologia da Escola de Design - CEDTec, Universidade do Estado de Minas Gerais - UEMG; Belo Horizonte, Minas Gerais, Brasil; nadjamourao@gmail.com. Trabalho apresentado no I Seminário Latino-Americano de Estudos em Cultura - SEMLACult, Foz do Iguaçu/PR, Brasil, 2017.

${ }^{2}$ PhD Gestão de Inovação Tecnológica/ECP França; Coord. Centro de Estudos em Design e Tecnologia da Escola de Design - CEDTec, Universidade do Estado de Minas Gerais - UEMG; Belo Horizonte, Minas Gerais/Brasil; rcengler@uol.com.br. Trabalho apresentado no I Seminário Latino-Americano de Estudos em Cultura - SEMLACult, Foz do Iguaçu/PR, Brasil, 2017.

${ }^{3}$ Mestre em Gestão Integrada do Território pela UNIVALE / Brasil. Doutoranda em Design; Centro de Estudos em Design e Tecnologia da Escola de Design - CEDTec da Universidade do Estado de Minas Gerais - UEMG; Belo Horizonte; Minas Gerais/Brasil; rmaciela@gmail.com.
} 
riquezas culturais, e o reconhecimento do legado deixado pelos antepassados, em atividades artesanais, repassadas entre as gerações.

Palavras-Chave: Povos tradicionais, recursos naturais, Identidade, artesanato, reserva ambiental.

\title{
Resumen
}

Este trabajo busca investigar los aspectos de los pueblos tradicionales y el manejo de los recursos naturales, en función de los valores socioambientales, de las comunidades al entorno de la Reserva Estadual de Desarrollo Sostenible Veredas del Acari, en función de la artesanía. Para ello, se utiliza la metodología de la investigaciónacción, por medio de la realización, de taller de Diseño, Identidad y Cultura. Se cree que el diseño social puede contribuir con el desarrollo sostenible en la región. La Reserva Ambiental del Acari garantiza la subsistencia y área de vegetación, que son recursos, para las comunidades, próximas a la región. La comunidad debe orientarse sobre los métodos adecuados, para la extracción de materiales y cómo evitar incendios, valorizando la biodiversidad local. En visitas técnicas, se identificaron algunas costumbres relacionadas con las tradiciones y actividades culturales. Se observaron cuáles son los conocimientos de producción artesanal y conceptos sociales, culturales y ambientales, que configuran en vínculo con la producción artesanal. El material didáctico, para la ejecución de talleres, fue preparado con la participación de los líderes comunitarios. Se verificó la compatibilidad con la realidad local, ofreciendo contenidos que pudieran auxiliar en el desarrollo de los productos artesanales. Las actividades de reconocimiento de las riquezas materiales e inmateriales, desarrolladas durante los talleres de diseño, estimularon la valorización del contexto histórico y de las tradiciones locales. Se realizaron análisis sobre las riquezas culturales, y el reconocimiento del legado dejado por los antepasados, en actividades artesanales, repasadas entre las generaciones.

Palabras clave: Pueblos tradicionales, recursos naturales, Identidad, artesanía, reserva ambiental.

\begin{abstract}
This work seeks to investigate the aspects of traditional peoples and natural resource management, according to the social and environmental values of the communities surrounding the State Sustainable Development Reserve Veredas do Acari, as a function of handicrafts. To do so, the methodology of action research is used, through the accomplishment of a Design, Identity and Culture workshop. It is believed that social design can contribute to sustainable development in the region. The Acari Environmental Reserve guarantees the subsistence and vegetation area, which are resources for the communities, close to the region. The community should be guided by appropriate methods, extraction of materials and how to avoid fires, valuing local biodiversity. In technical visits, some customs related to cultural traditions and activities were identified. It was observed the knowledge of artisanal production and social, cultural and environmental concepts, which are linked to the artisanal production. The didactic material for workshops was prepared with the participation of community leaders. The compatibility with the local reality was verified, offering contents that could help in the development of the artisan products. The activities of recognition of material and immaterial wealth, developed during the design workshops, stimulated the valorization of the historical context and the local traditions. Analyzes were carried out on the cultural riches, and the recognition of the legacy left by the ancestors, in artisanal activities passed on between generations.
\end{abstract}

Keywords: Traditional peoples, natural resources, identity, handicrafts, environmental reserve.

\section{Introdução}

A análise da destruição e da conservação dos recursos naturais permitiu perceber a existência de populações capazes de utilizar, e ao mesmo tempo conservar tais recursos. Estes grupos humanos passaram a ser chamados de povos tradicionais. São consideradas comunidades tradicionais os povos indígenas, as comunidades remanescentes de quilombos, os caboclos ribeirinhos, as comunidades tradicionais urbanas, as populações tradicionais 
marítimas, que se subdividem em pescadores artesanais e os caiçaras, entre outras, conforme Santana e Oliveira (2005).

Em cada região do território brasileiro, as populações tradicionais apresentam traços culturais que as diferenciam dos demais povos no entorno. Os povos negros ou miscigenados que, por muito tempo, ficaram em relativo isolamento nas áreas do cerrado e outros biomas, também são populações tradicionais. Estes povos aprenderam a retirar da natureza recursos para alimentação, utensílios e artesanato. Conforme sua história e hábitos locais são chamados de quilombolas, geraizeiros, vazanteiros, sertanejos e ribeirinhos. O Ministério do Meio Ambiente reconhece que estas comunidades aproveitam os recursos do bioma geralmente de forma racional, equilibrada e sem impactar significativamente os ecossistemas (MMA, 2004).

A inserção dos povos tradicionais no contexto do meio ambiente passou a existir a partir da discussão sobre a presença de seres humanos nas Unidades de Conservação. Os países pioneiros na criação de Unidades de Conservação estabeleceram uma tradição de que dentro das mesmas, não poderia haver a presença dos humanos. Porém, conforme Silva (2010), no Brasil, considerado um país em desenvolvimento, é recente a criação das áreas de preservação e conservação. Esta atitude despertou maior atenção na relação entre o homem e o meio ambiente. Foi observado que realmente existem populações cuja ação é altamente benéfica para a conservação do meio ambiente.

Uma vez que vivem de tais recursos naturais, as populações tradicionais também devem reconhecer que o meio onde residem deve ser fiscalizado por eles próprios. Olmos (2009) relata que os povos tradicionais têm um histórico impressionante de domesticação de plantas e animais que gerou o que são, efetivamente, novas espécies. Nas Américas, os povos pré-colombianos cultivaram alimentos como: a abóbora, o milho, a batata, a mandioca, o feijão, a pupunha sem espinho e a quinoa. Cita-se entre as espécies animais de origem sulamericana: as alpacas, lhamas, cobaias e o cão pelado peruano. Esses são resultados de seleção artificial feita ao longo de muitos anos, e diferentes de seus ancestrais selvagens, são populações excluídas dos núcleos dinâmicos da economia nacional.

Ao longo de toda a história do Brasil, as populações tradicionais adotaram o modelo da cultura rústica, refugiando-se nos espaços menos povoados, onde a terra e os recursos naturais eram abundantes. "Foi possibilitada sua sobrevivência e a reprodução desse modelo sociocultural de ocupação do espaço e exploração dos recursos naturais, com inúmeros 
variantes locais determinados pela especificidade ambiental e histórica das comunidades que neles persistem" (OLMOS, 2009, p.1).

"As populações tradicionais têm muitíssimo a contribuir para o uso sustentável e a conservação de recursos naturais”. Defende a antropóloga Manuela Carneiro da Cunha, em entrevista ao site do Instituto Sociedade, População e Natureza - ISPN (2008). Há um tempo, acreditavam-se orientações globalizadas poderiam ensinar às populações locais o que seria melhor para eles. Houve uma recusa das culturas locais, só se pensava na produtividade, o que reduziu drasticamente a diversidade agrícola. Pensando globalmente, foram destruídos sistemas agrícolas engenhosos, desenvolvidos durante séculos e adaptados tanto ao ambiente específico quanto às condições de vida dos agricultores. O movimento atual é de saber ouvir o que as comunidades tradicionais têm a ensinar, conforme ISPN (2008).

Há uma questão que se mantêm em relevância: são os vestígios que o ser humano deixa no meio ambiente. Algumas espécies, entre animais e vegetais, não toleram as atividades humanas e desaparecem no decorrer dos tempos, segundo a União Internacional pela Conservação da Natureza (IUCN). Dessa forma, faz-se necessário que sejam efetivados investimentos, pesquisas e projetos, que contribuam na capacitação de comunidades tradicionais e moradores agroextrativistas, em regiões próximas a reservas e unidades de conservação.

É realidade para comunidades que residem em áreas próximas aos parques e às áreas de reserva para promoção do desenvolvimento sustentável, o uso sustentável da biodiversidade do cerrado, que serve como geração de renda, segurança alimentar e qualidade de vida à população regional. O cerrado proporciona às comunidades plantas medicinais, frutas nativas, criação de abelhas, manejo de animais silvestres, ecoturismo, condimentos, artesanato entre outros. "Esses povos fazem parte do patrimônio histórico e cultural brasileiro e detêm um amplo conhecimento tradicional da biodiversidade" (CARVALHO, 2005 apud SARAIVA \& SAWYER, 2007, p.2).

Por exemplo, durante o Encontro dos Povos do Grande Sertão Veredas - próximo ao Parque Nacional Grande Sertão Veredas (no município de Chapada Gaúcha, em Minas Gerais) diversas comunidades se apresentam em manifestações culturais que as tornam únicas. O objetivo do evento é reunir os povos tradicionais da região, por meio de atividades culturais, para tratarem de questões comuns no território. Algumas comunidades estão representadas nos coloridos estandartes, que são expostos no evento, conforme figura 1. 


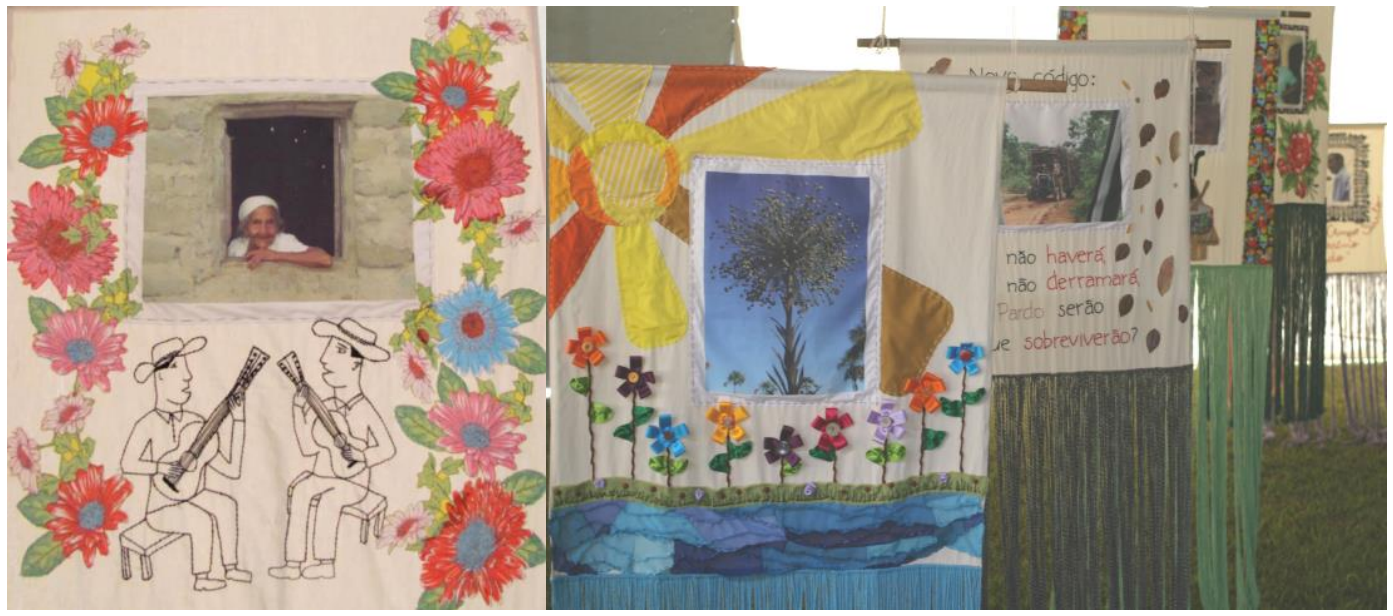

Figura 1- Estandartes que representam algumas comunidades tradicionais na região.

Fonte: Equipe da Pesquisa, 2016.

Este trabalho busca investigar os aspectos dos povos tradicionais e manejo dos recursos naturais, em função dos valores socioambientais das comunidades ao entorno da Reserva Estadual de Desenvolvimento Sustentável Veredas do Acari, por meio da produção artesanal. Para tanto, utiliza-se a metodologia da pesquisa-ação, realizando oficinas de "Design, Identidade e Cultura”. Essas oficinas foram desenvolvidas com a participação de lideranças locais. Acredita-se que o design social pode contribuir com o desenvolvimento sustentável na região. A Reserva Ambiental do Acari, localizada no Município de Chapada Gaucha - Minas Gerais, garante a subsistência para as comunidades próximas à região.

\subsection{Povos e cultura na Região do Vale do Urucuia}

As comunidades do Vale do Urucuia vivenciaram muitos conflitos envolvendo os grandes fazendeiros da região, entre o final do século dezenove e inicio do século vinte. Os intitulados coronéis, fazendeiros proprietários de grandes territórios, comandavam grupos de jagunços, entre agregados e vaqueiros, para a guarda de seus patrimônios e disputas territoriais. Conforme Ibama/Funatura (2003) apud Souza (2006), os jagunços tornaram-se bandos que guerreavam no sertão em nome de seu chefe, uns aliados, outros contra o governo, e se tornaram personagens históricos característicos da região. Como mito popular, muito ainda se comenta sobre o passado. Vaqueiros e descendentes guardam fisicamente e na memória, as características herdadas dessa cultura. Observam-se também as características expressas no vestuário, no jeito de falar e de se relacionar, na alimentação, nas rodas de música e de conversa, ou seja, na vida cotidiana do sertanejo. 
Houve um projeto de assentamento dirigido à comunidade de Serra das Araras, que provocou várias mudanças, durante o período da implementação das políticas agropecuárias para a região, nos anos 70. A região do noroeste mineiro tornou-se área de ocupação territorial denominada Projeto de Assentamento Dirigido a Serra das Araras - PADSA. Essa ação foi realizada pela Fundação Rural Mineira - Ruralminas, um órgão estadual da Secretaria Estadual de Agricultura, Pecuária e Abastecimento, responsável por projetos, conforme Ibama/Funatura (2003); IBGE (2008, p.2).

Após estudos topográficos específicos e loteamento feito pela Ruralminas, cerca de dez famílias oriundas do sul do país iniciaram a ocupação ainda no ano de 1976, conforme Ibama/Funatura (2008). Este foi o início do cenário que resultou especialmente na Vila dos Gaúchos, atualmente município de Chapada Gaúcha.

Na figura 2, apresenta-se um esquema de mapas em escala proporcional com a localização do Município de Chapada Gaúcha em Minas Gerais e imagens da Reserva Estadual de Desenvolvimento Sustentável do Acari, tema desse trabalho.
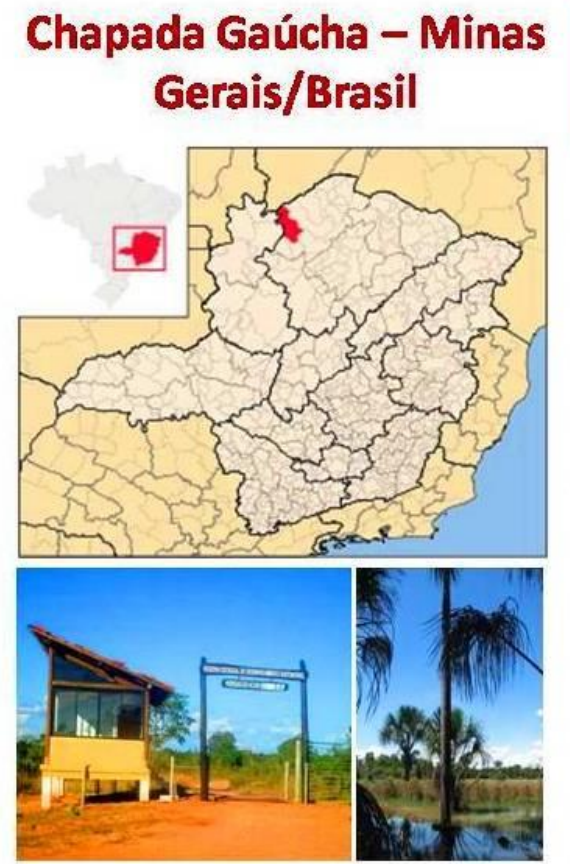

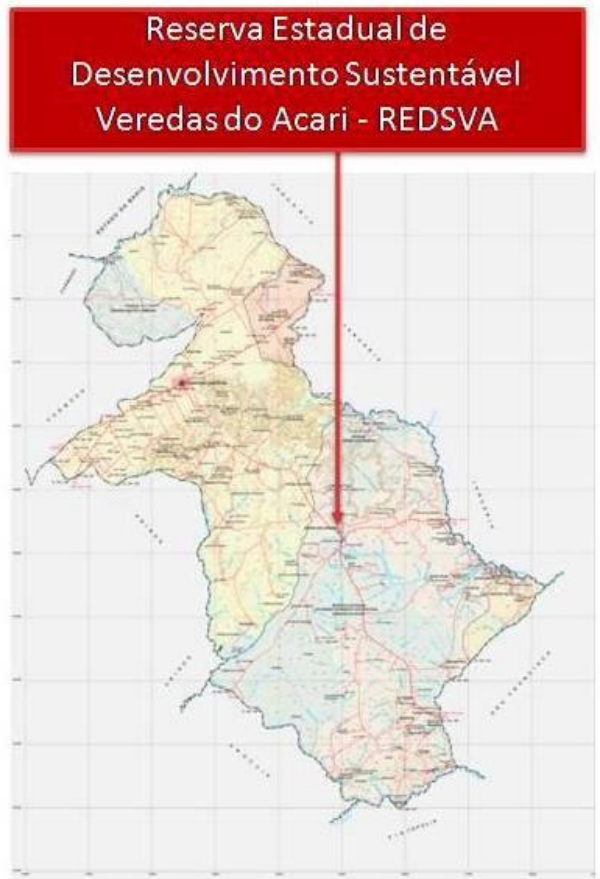
Desenvolvimento Sustentável Veredas do Acari - REDSVA

Figura 2 - Chapada Gaúcha e REDSVA

Fonte: Equipe da Pesquisa, 2016.

Muitos foram os desentendimentos ocorridos entre mineiros e gaúchos. Agricultores gaúchos perderam seus investimentos na agricultura. $O$ plantio de arroz no início do 
povoamento fracassou em sua grande maioria. "A falta de apoio financeiro e de assistência técnica combinou-se com a criação extensiva de gados que circulavam e se alimentavam nas áreas de plantio". O gado criado solto, por fazendeiros e posseiros mineiros residentes nos arredores, foi recuado para manutenção do sistema de plantio, SALGADO (2010, p.56) apud (ZATZ, 2004).

A cultura de preservação do meio ambiente vinculada ao extrativismo vegetal para o aproveitamento integral dos frutos do cerrado está ainda em desenvolvimento. Os produtos coletados geralmente por comunidades tradicionais são destinados ao autoconsumo, de acordo com Salgado (2010) apud Funatura (2008); Mosaico (2009). Grupos de trabalho social e cooperativas atuam para expansão do manejo sustentável e desenvolvimento local.

A mistura de populações diferenciadas, gaúchos (fixados na região pelo assentamento PADSA) e sertanejos principalmente, sucedeu em aspecto diferenciado aos hábitos da cidade. Os gaúchos carregaram as festas e as danças do sul para os sertões. Conforme relato dos membros do Centro de Tradições Gaúcha Chama Crioula de Chapada Gaúcha, o tradicionalismo gaúcho é fortalecido pelo Movimento Tradicionalista Gaúcho do Planalto Central. Com o passar dos anos, a convivência entre os povos, começa a surtir efeitos socioeconômicos. Os hábitos do sul entre os sertanejos foram compartilhados, aos poucos. Algumas cenas podem ser identificadas na figura 3, como a cavalgada gaúcho e sertanejo, as canções em viola, o uso do chimarrão no sertão, as danças folclóricas gauchas, entre outras tradições locais.

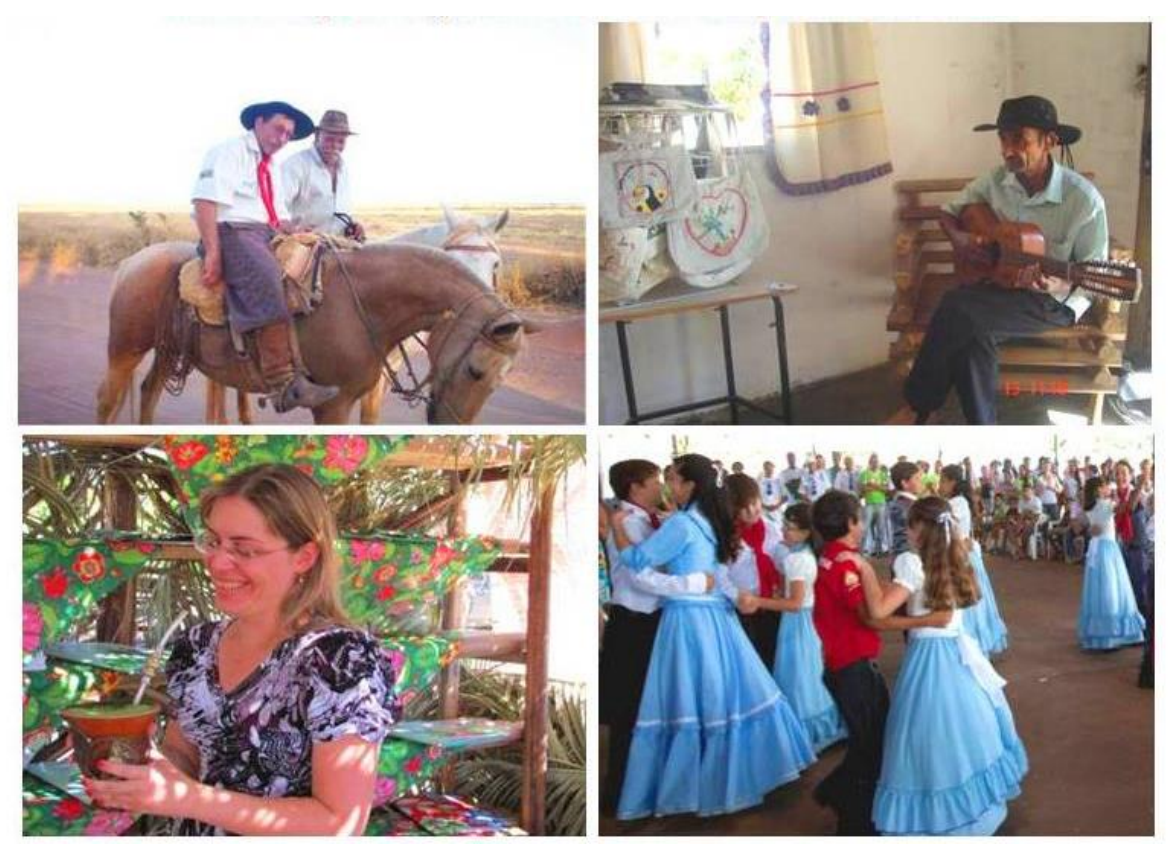

Figura 3 - Sertanejos e gaúchos, em Chapada Gaúcha.

Fonte: Equipe da Pesquisa, 2016. 


\subsection{Conceitos de comunidade e identidade}

O conceito de comunidade, conforme Tonnies (1987) trata de uma forma especial sobre as relações humanas, cuja natureza se funda num conjunto de estados afetivos, hábitos e tradições. Para o autor, o que define a comunidade é diferente das ações da sociedade que vem a ser uma forma de relações cuja natureza, ao contrário, constitui-se no interesse individual, racional de cada um. Uma construção sociocultural, fundamentada em artifícios, descobertas, ferramentas, e instrumentos, a saber, em símbolos organizados em códigos. Para construção de identidades é preciso o conhecimento de símbolos que fazem parte do contexto local que a comunidade está inserida em conjunto de seus objetivos comuns.

Defini-se identidade como o processo de construção de significados com base em um atributo cultural, ou ainda um conjunto de atributos culturais inter-relacionados, os quais prevalecem sobre outras fontes de significado, conforme Castell (1999).

Hall (2006) nos fala que as velhas identidades, que por tanto tempo instabilizaram o mundo social, estão em declínio, fazendo surgir novas identidades e fragmentando o indivíduo moderno. $\mathrm{O}$ autor ainda acrescenta que a questão da identidade está relacionada com o caráter da mudança na modernidade tardia; em particular, ao processo de mudança conhecido como globalização e seu impacto sobre a identidade cultural.

Massey (2000, p. 185) aponta que a multiplicidade de identidades é provocada pela acumulação de elementos produzidos no tempo e no espaço ao longo da história. Segundo a autora, "os lugares não tem identidades únicas ou singulares: eles estão cheios de conflitos internos". O conflito tem início na identificação da fonte que a singulariza verdadeiramente e que não está na história, não está internalizada. É, muitas vezes, uma invenção ou uma reprodução. As identidades, na maioria das vezes, são construídas e reconstruídas no tempo e nas fronteiras com novas culturas (MACIEL, 2011, p.34).

\section{Metodologia e estudo do território}

O objetivo do problema foi abordado no método descritivo, utilizando dados qualitativos. O método de investigação adotado foi o estudo de caso, por meio da observação em pesquisa-ação, realizando uma oficina de arte e cultura, para contribuir com a produção artesanal e para o desenvolvimento sustentável na região. 
Conforme Yin (2005, p. 121), a observação participante é uma modalidade especial de observação, na qual o "pesquisador assume uma variedade de funções dentro de um estudo de caso e pode, de fato, participar dos eventos que estão sendo estudados”.

A comunidade de Serra das Araras, em Chapada Gaúcha, Minas Gerais, escolhida pela possibilidade de investigação em produção artesanal, com a participação de povos tradicionais e de visitação aos artesãos. Nessa comunidade foi verificado que o conhecimento do artesanato é vinculado à agricultura familiar, com incidência de identidade nos produtos. Essa comunidade se localizada no setor centro-sul do município, próximo ao Parque Estadual Serra das Araras e a Reserva de Desenvolvimento Sustentável Veredas do Acari - RDSVA.

A Reserva Estadual de Desenvolvimento Sustentável Veredas do Acari possui uma área de 60.975,31 hectares, abrangendo o município de Chapada Gaúcha e também o município de Urucuia (IEF, 2011). Está localizada na Microrregião de Januária e Macrorregião do Norte de Minas, sendo a primeira Unidade de Conservação (UC) desta categoria dentro do Estado de Minas Gerais. Na imagem da figura 4, um panorama do Parque Estadual Serra das Araras e da Reserva Estadual de Desenvolvimento Sustentável Veredas do Acari.

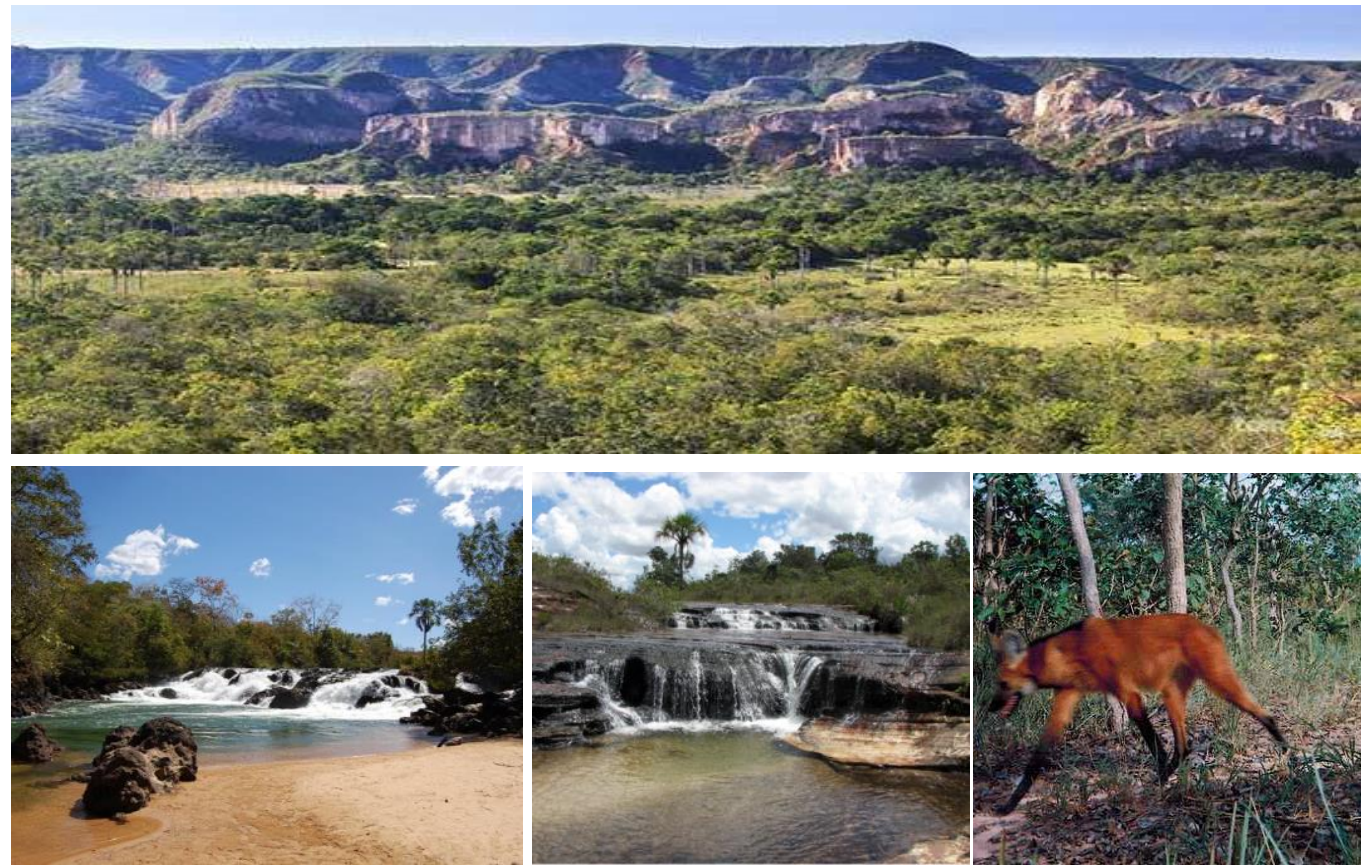

Figura 4 - Parque Estadual Serra das Araras e REDSVA.

Fonte: naturezabrasileira.com.br e IEF, 2016. 
A Reserva Estadual de Desenvolvimento Sustentável Veredas do Acari foi criada pelo Decreto Estadual s/n ${ }^{\circ}$, de 21/10/2003, com o objetivo de proteger e conservar o bioma Cerrado e na Bacia do rio São Francisco, no Estado de Minas Gerais. Tem como objetivos: propiciar o manejo sustentável dos recursos naturais às populações tradicionais residentes dentro e entorno da referida unidade de conservação; promover a pesquisa de produtos do cerrado, bem como a proteção da biodiversidade e dos aquíferos; e incentivar a educação ambiental e ecoturismo, conforme Instituto Estadual de Florestas de Minas Gerais (2011).

Os dados do levantamento inicial foram realizados em função da dissertação de mestrado em Design, da Universidade do Estado de Minas Gerais que, a partir de 2010, serviram de suporte à estrutura do projeto. Foram cadastrados e entrevistados 35 moradores e pessoas que atuam com o público local (voluntários). As entrevistas foram realizadas com os participantes dos cursos de Manejo e beneficiamento dos frutos do Cerrado, que residem em áreas diversas do município. Foi realizada uma visita à comunidade de Serra das Araras, e à comunidade do Rio Catarina para verificação de dados registrados.

A Reserva Ambiental do Acari garante a subsistência e vegetação utilizada nas comunidades próximas à região. O gerente da Reserva Estadual Veredas do Acari e do Parque Estadual Serra das Araras, alerta que a comunidade deve ser orientada sobre a forma adequada para a extração de materiais e como proceder para evitar incêndios.

\subsection{Insumos e resíduos vegetais}

De acordo com MOURÃO (2011, p.20) os “resíduos vegetais" são as partes e produtos das vegetações que são lançadas no meio ambiente, com a possibilidade de serem reutilizadas como adubo natural, alimento da fauna e como insumo para o artesanato. Destacam-se as flores, folhas, sementes e galhos secos, espalhados ao solo, e troncos danificados por efeito da atuação de insetos e das forças físicas - tempestades e incêndios. Nesta análise, incluí-se a denominação de "resíduos florestais", que agrega valores específicos de áreas com mata espessa, principalmente após queimadas, conforme Foelkel (2007). Incluem-se os "insumos" - as plantas, os frutos, as flores, as fibras e outros produtos do agroextrativismo, conforme Goulart (2004).

Clark (1979) apud Brito e Couto (1980) esclarece que devido à necessidade de uma nomenclatura padrão para componentes, para facilitar a definição do que é resíduo da exploração florestal, é necessário apresentar um modelo de classificação. Destacam-se os seguintes termos (descritos no glossário desta pesquisa): árvore completa; touça e raízes; parte 
aérea da árvore; fuste total; fuste; ponteiro; copa; ramos; folhagem. Relata ainda que o resíduo florestal depende das práticas de exploração florestal. Quando se utiliza apenas do fuste sem casca, o resíduo pode ser a casca, a copa, touça e raízes.

\subsection{Uso sustentável da biodiversidade do Cerrado}

O uso sustentável da biodiversidade do Cerrado é realidade para comunidades que residem em áreas próximas aos parques e às áreas de reserva para promoção do desenvolvimento sustentável, servindo como geração de renda, segurança alimentar e qualidade de vida à população regional. O cerrado proporciona às comunidades plantas medicinais, frutas nativas, criação de abelhas, manejo de animais silvestres, ecoturismo, condimentos, artesanato entre outros.

Inúmeras populações vivem no Cerrado e sobrevivem dos seus recursos naturais. $\mathrm{O}$ desafio é tornar esta relação sustentável em todos os aspectos. Os insumos do Cerrado são utilizados como geração de renda, segurança alimentar e qualidade de vida para as comunidades. Entre as comunidades que residem no Cerrado estão os povos tradicionais. "Esses povos fazem parte do patrimônio histórico e cultural brasileiro e detêm um amplo conhecimento tradicional da biodiversidade" (CARVALHO, 2005 apud SARAIVA \& SAWYER, 2007, p.2).

A Bacia hidrográfica do rio Urucuia nasce na Serra Geral de Goiás, fronteira desse Estado com Minas Gerais. Suas águas vão deslizando entre morros e chapadões, no sentido oeste-leste até chegar ao rio São Francisco. Os córregos que formam suas nascentes estão nos municípios de Formosa e Cabeceiras, em Goiás, e Buritis - Minas Gerais. Geologicamente, a maioria dos tipos de solo dessa bacia é parte da Formação Urucuia, que apresenta idade variável entre 80 e 50 milhões de anos (MENDES, 2011).

\subsection{Serra das Araras: comunidade e artesanato}

A Vila de Serra das Araras, reconhecida por seu povo pacato, é uma das principais localidades do município, constituindo um importante elemento histórico, cultural e ambiental para o mesmo. Com cerca de 1.000 habitantes, o distrito é ponto de passagem para viajantes que cruzam a chapada em direção ao norte de Minas Gerais e os que a ela retornam. Ainda com forte ligação com o município de São Francisco, do qual era distrito até o ano de 1996, sua demanda de apoio de comércio e serviços se dá especialmente com a região norte mineira, com destaque para a cidade de Januária (SALGADO, 2010 apud ZATZ, 2004). 
Sua origem, fortemente marcada na memória popular, está vinculada a Santo Antônio, o padroeiro da comunidade. Segundo consta, há cerca de 100 anos (com relatos de até 150), um vaqueiro encontrou a imagem do santo no alto da Serra. Emocionado ele a levou para sua casa, mas na manhã seguinte a imagem havia desaparecido. Este fato se repetiu várias vezes até que a comunidade construiu uma capela e um padre a benzeu, fazendo com que a imagem permanecesse no local, angariando desde então procissões e homenagens ao santo padroeiro (IBAMA/FUNATURA, 2003).

As romarias ao santo padroeiro impulsionaram o agrupamento humano inicial ocorrido na localidade. Em adição ao papel religioso em seu processo de formação, o distrito de Serra das Araras também foi povoado com o advento de novas culturas e lavouras para a região, que atraíram inúmeros trabalhadores locais, incentivando-os a saírem da zona rural para morarem no distrito. Nesse período o distrito cresceu e progrediu com a implantação de empresas e o aquecimento de sua economia. Esta nova forma de cultivo provocou o crescimento especialmente em Serra das Araras, onde muitos trabalhadores mineiros se instalaram e firmaram residência. A Vila foi ampliada e a estrada que liga Januária à Chapada foi refeita e ampliada (SALGADO, 2010, p.64 apud ZATZ, 2004).

Todos os eventos religiosos são comemorados com muita tradição; a participação da comunidade é um destaque, pois geralmente, nestas festas, muitas turistas e amigos visitam a cidade. A Festa de destaque é a Festa de São Antonio de Serra das Araras, sempre na semana de 13 de junho. Entre os festejos católicos ocorrem barraquinhas, produtos de outras regiões e shows musicais que atraem diversos públicos.

A Associação de Bordadeiras e Artesãos Rurais de Serra das Araras produz diversos trabalhos artesanais com o buriti, que são expostos na loja da associação e comercializados sob encomenda. A associação participa da Rede Artesol que oferece pelo site produtos como: esteiras, cestos, caixas, terços, flores, araras, brinquedos, mobiliário e outros. Para a produção destes objetos, o IEF acompanha a extração dos "talos" secos de buritis, que estão localizados na Reserva do Araci para o Desenvolvimento Sustentável. As soluções para a extração e produção são geradas no próprio grupo.

Os membros da associação trabalham juntos e são, na maioria, mulheres (figura 5). Elas relatam que as encomendas e vendas ainda não são suficientes, mas os produtos artesanais são apreciados por muitos turistas e garantidos pelas parcerias.
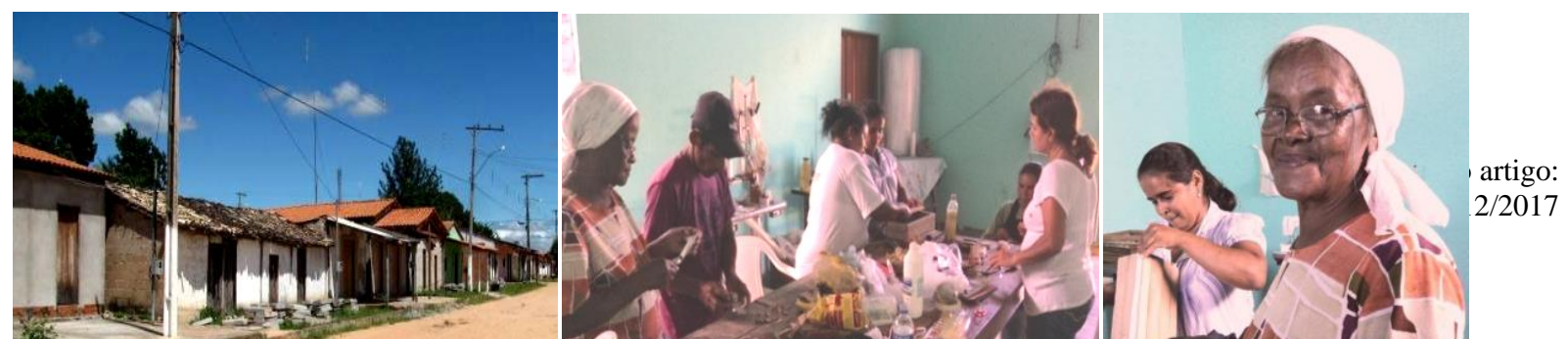
Das técnicas e materiais empregados, utilizam tecidos e linhas para confecção dos bordados, em bolsas, camisetas de malha e outros adornos. Aproveitam a palha e os talos de buriti para objetos e molduras dos bordados em quadros de adorno. Utilizam também sementes e folhas de espécies vegetais diversas do cerrado em produção artesanal.

\section{Oficinas Design, Identidade e Cultura}

Utiliza-se o termo "oficinas" como um tipo de atividade prática que promove o saber de um conhecimento, em curto tempo; cujo aprendizado se realiza em ambiente sugerido. Neste caso, desenvolveu-se uma proposta sintética com conteúdos básicos de arte educação e cultura, especificamente para o público das comunidades da pesquisa.

Na primeira etapa são desenvolvidas atividades para sensibilização e observação do contexto socioambiental, através de elementos para percepção das cores, texturas, formas, ambiente e da cultura. Na segunda etapa são aplicadas atividades práticas, utilizando resíduos vegetais coletados pelos participantes. Nesta prática, são observadas as técnicas, a percepção espacial e criatividades na utilização dos materiais empregados pelos artesãos.

Estas atividades visam estimular a participação ativa da comunidade, como intervenção no contexto social, para possibilitar a solução de dificuldades provenientes da realidade da região. Na figura 6, apresenta-se um estudo para artesanato de arranjo de flores de folhas, com miolo de semente de jabota (Hymenaea courbaril) e acabamento de chichá-docerrado (Sterculia strita), em uma base de cabaça (Lagenaria siceraria). Na figura 7, uma bolsa decorada com diversas sementes locais, como jatobá. O importante desta etapa é o reconhecimento das espécies vegetais do cerrado, em especial, do entorno da Reserva Estadual de Desenvolvimento Sustentável Veredas do Acari - REDSA. Em produto final, figura 8, destaca-se o oratório para Santo Antonio, todo em buriti (Mauritia flexuosa), que é um dos exemplos do artesanato local. 

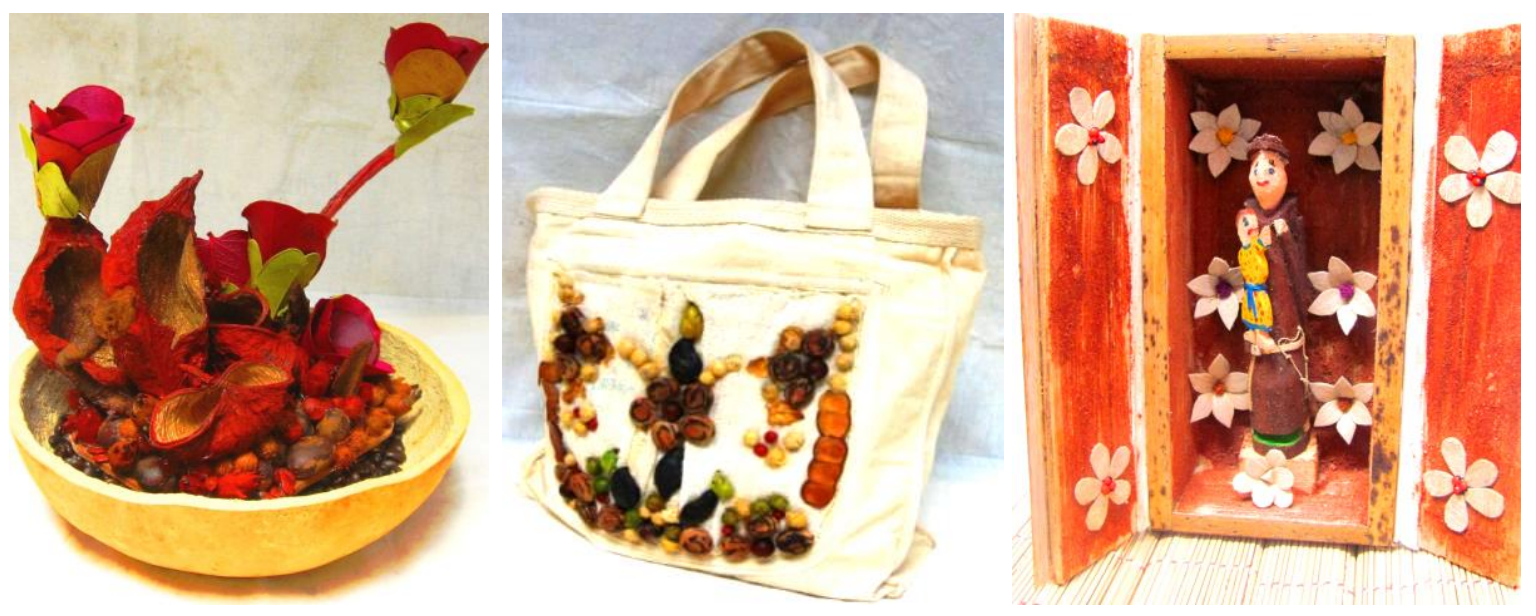

Figura 6 - Arranjo decorativo de chichá-do-cerrado e cabaça.

Figura 7 - Bolsa de tecido, decorada com sementes de espécies locais, como jatobá.

Figura 8 - Oratório e Santo Antonio, confeccionados com buriti.

Fonte: Equipe da pesquisa, 2016.

As oficinas possibilitam ao pesquisador observar o grupo no desenvolvimento das atividades artesanais (materiais e técnicas), na apropriação dos conteúdos e da identidade. Têm como objetivo a integração dos participantes, incentivando-os para troca de informações com a equipe do projeto. Despertou-se um interesse pela percepção ambiental, que contribuem aos artesãos, a conhecerem melhor o meio ambiente no qual estão inseridos. Saber qual a espécie que é adequada para novos produtos artesanais passou a se um novo desafio das artesãs, que utilizam dos recursos da Reserva Estadual de Desenvolvimento Sustentável Veredas do Acari - REDSA, para uso no artesanato. Observaram-se quais os conhecimentos de produção artesanal e conceitos sociais, culturais e ambientais, estabelecendo vínculo com os produtos artesanais.

As artesãs, no período de acompanhamento da pesquisa, declararam que o projeto estimula o uso de novas técnicas e aproveitamento de materiais. Acreditam que aos poucos a comercialização aumentará, pois a associação é ainda recente e está desenvolvendo contato com outras associações e instituições, como a Central Veredas de Artesanato organizada em Rede Solidária. Compreendem que é preciso investir no desenvolvimento das técnicas de produção e da utilização de materiais.

\section{Espécies vegetais compatíveis à produção artesanal}


O resíduo vegetal é de fundamental importância na ciclagem de nutrientes. Como adubo das plantas, enriquece o solo de minerais que novamente geram o ciclo biológico. Especial importância deve ser conferida a extração de frutos e sementes. Cada espécie possui na natureza um número mínimo de sementes indispensáveis à sua manutenção. Esta quantidade imprescindível é resguardada pela produção da espécie, de sementes, folhas e frutos, superior a mesma. Foi verificada a necessidade de conhecimento prévio sobre uma planta para saber como preservá-la. A extração incorreta desse recurso pode levar a extinção local da espécie.

A produção artesanal, com recursos dos insumos e resíduos vegetais dos biomas brasileiros, é um assunto amplo e multidisciplinar, que possibilita diversos tipos de análises conforme o ponto de vista do pesquisador. Trata-se neste trabalho apenas de alguns dados comparativos, considerando o aproveitamento dos materiais citados. Foi confeccionado um pequeno catálogo para contribuir no conhecimento das espécies vegetais locais, Figura 10 "Espécies vegetais do Cerrado: materiais para produção artesanal”, acesso disponibilizado pelo link: 〈https://issuu.com/cedtec/docs/cat_logo_nadja〉.
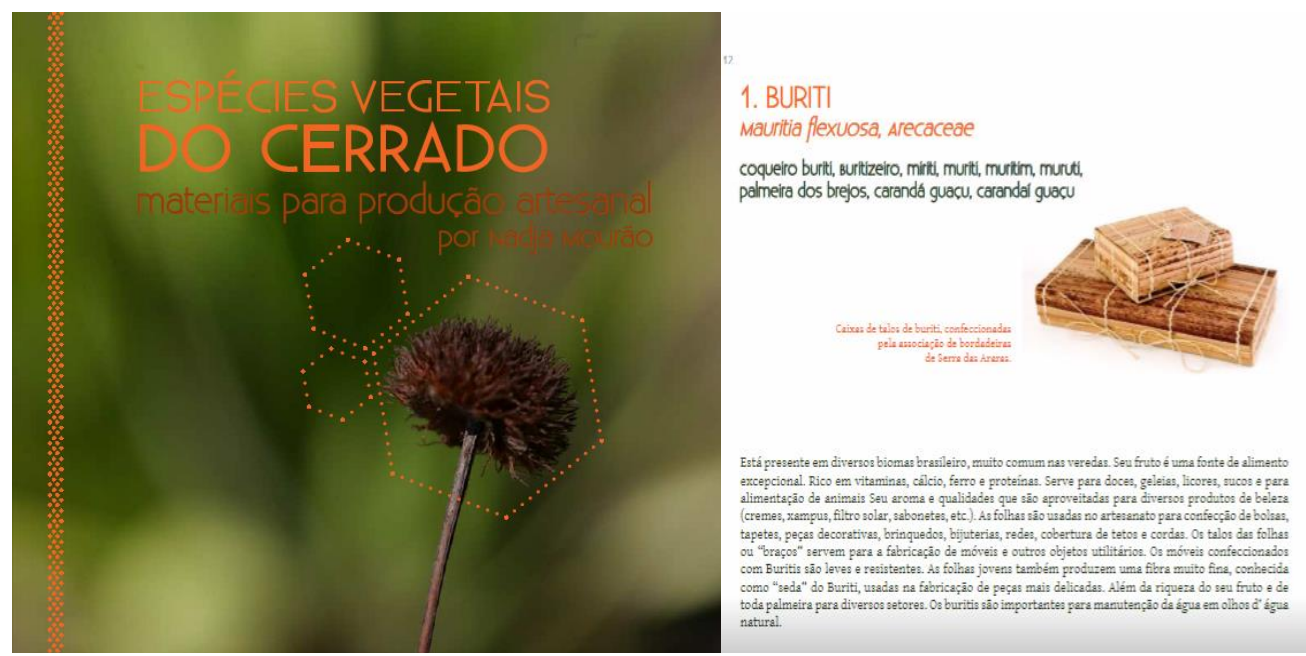

Figura 9 - Catálogo "Espécies vegetais do Cerrado: materiais para produção artesanal" Fonte: https://issuu.com/cedtec/docs/cat_logo_nadja

Portanto, é necessário estimular, tanto aos artesãos quanto aos comerciantes, para o entendimento da estrutura e funcionamento do ecossistema a ser explorado. Deve-se enfatizar o ciclo biológico de cada espécie, a fim de promover um manejo adequado e manter a taxa de produtividade necessária à preservação. Esta é uma das funções dos órgãos municipais e estaduais, mas é também de todos que estão inseridos no sistema. 
A diversidade de materiais e possibilidades de uso dos mesmos induz a uma ausência de padronização, quanto às ferramentas e técnicas empregadas nesse tipo de produção artesanal. Está inserido nesse processo, um alto caráter de experimentação e, consequentemente, de inovação. Os dados levantados indicaram uma predominância de comercialização de sementes e folhas, em detrimento de outros resíduos vegetais. Foi possível perceber que muitas espécies do Cerrado já são utilizadas, como: Bate Caixa, Jacarandá, Guatambu e Buriti.

\section{Conclusão}

A Reserva Estadual de Desenvolvimento Sustentável Veredas do Acari, contribui para a preservação da cultura e tradições das comunidades ao entorno, por meio dos recursos naturais para a produção artesanal. Os valores socioambientais fazem parte das orientações para utilização das espécies vegetais e a utilização da arte e cultura pode ser um facilitador para a transformação e expansão de potenciais.

Assim, algumas considerações devem ser destacadas em relação às possíveis contribuições das oficinas de Design, Identidade e Cultura aplicadas pra a comunidade local. Os artesãos das comunidades se posicionaram de forma bastante receptiva na aplicação de oficinas de design. Os participantes se demonstraram ávidos para conhecerem os princípios sobre as cores, formas, texturas e possibilidades de utilização dos materiais que eles já possuem.

As oficinas possibilitaram também o olhar criativo, a vontade de experimentar e inovar. Através das técnicas, os participantes das oficinas perceberam a riqueza ao redor de suas residências, o espaço em dimensões maiores do que estavam habituados a "ver". Promover este olhar significa estimular o desenvolvimento de um amplo espectro de possibilidades de inovação, cuja base é observar e utilizar os mais simples recursos de forma que a funcionalidade aprimore.

A opção de participar de uma atividade fora do contexto, como as oficinas propostas aos artesãos, incentivaram o reconhecimento das riquezas imateriais e a valorização do contexto histórico cultural local. Foram executadas algumas análises pelos participantes, como as contribuições das atividades artesanais como legado de gerações a gerações Eles perceberam que estes conhecimentos configuram-se na identidade da comunidade. Os artesãos rurais, habituados ao ríspido trabalho com a terra, necessitam de estimulo para 
desenvolver novas habilidades. Ao valorizar aspectos ambientais, a beleza e a estética, o olhar se converge ao desejo de novas conquistas.

Por fim, deixa-se o registro singular de algumas espécies vegetais da Reserva Estadual de Desenvolvimento Sustentável Veredas do Acari, para a produção artesanal da comunidade de Serra das Araras. Acredita-se que as atividades do design social têm entre as suas atribuições, recursos que podem contribuir com o desenvolvimento sustentável para os povos tradicionais.

\section{Referências}

BRITO, J. O. ; COUTO, H. T. Z. Inventário de resíduos florestais. Serie Técnica IPEF. Piracicatu. v.1,n.2.p.A1-A, 13.jul.1980. Disponível em: http://www.ipef.br/publicacoes/stecnica/nr02/cap01.pdf. Acesso em: 20 jun. 2017.

CARVAlHO, I. S. H. Potências e limitações do uso sustentável da Biodiversidade do Cerrado: um estudo de caso da Cooperativa Grande Sertão Veredas do Norte de Minas Gerais. Resumos do V CBA - Uso e Conservação de Recursos Naturais, 2005.

CASTELLS. M.. O poder da identidade. São Paulo: Paz e Terra, 1999.

CENTRO DE TRADIÇÕES GAÚCHAS CRIOULA. Disponível em: http://econosoft.com.br/lista_empresas/MINAS-GERAIS/CHAPADAGAUCHA/C/03205917000110-CENTRO-DE-TRADICOES-GAUCHAS-CHAMACRIOULA. Acesso em: 18 jun. 2017.

FOELKEL, C. Gestão ecoeficiente dos resíduos florestais. Lenhosos da eucaliptocultura.2007. Eucalyptus Online Book \& Newsletter. Disponível em: http://www.eucalyptus.com.br/capitulos/PT07_residuoslenhosos.pdf. Acesso em: 20 Jun. 2017.

FUNDAÇÃO PRÓ-NATUREZA - FUNATURA. Levantamento Socioeconômico das Comunidades localizadas no Parque Nacional Grande Sertão Veredas, 1998.

FUNDAÇÃO PRÓ-NATUREZA - FUNATURA. Plano de manejo do Parque Nacional Grande Sertão Veredas. Brasília, julho de 2003.

GOULART, L. H. S. D. Dicionário do Agrônomo. São Paulo: Editora Rigel, 2004.

HALL, S.. A identidade cultural na pós-modernidade. Tradução: Tomaz Tadeu da Silva, Guaracira Lopes Louro. 4. ed. Rio de Janeiro: DP\&A. 2000.

IBGE.INSTITUTO BRASILEIRO DE GEOGRAFIA E ESTATÍSTICA. 2008. Disponível em:

http://www.ibge.gov.br/home/presidencia/noticias/noticia_visualiza.php?id_noticia=1099

\&id_pagina=1\&titulo=Mulheres-com-nivel-superior-recebem-60\%-do-rendimentodoshomens. Acesso em: 20 jun. 2017.

INSTITUTO ESTUDUAL FLORESTAS - IEF. Reserva Estadual de Desenvolvimento Sustentável Veredas do Acari. Disponível em: http://www.ief.mg.gov.br/noticias/3306-nova- 


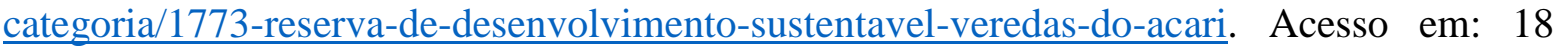
jun. 2017.

INSTITUTO ESTUDUAL FLORESTAS - IEF. Áreas protegidas, 2011. Dissertação em Ciências Florestais. Disponível em: http://www.ief.mg.gov.br/areas-protegidas/209. Acesso em: 18 jun. 2017.

MACIEL, R. Ibituruna, a marca de um território: design e identidade em apropriações simbólicas da paisagem em Governador Valadares. 2011. 195 fls. Dissertação (mestrado). Universidade Vale do Rio Doce, Governador Valadares. 2011.

MASSEY, D. Um sentido global do lugar. In: ARANTES, Antônio (Org.). O espaço da diferença. Campinas: Papirus, 2000. p. 176-185.

MENDES, X. História do vale do Rio Urucuia em Minas Gerais. Academia Planaltinense de Letras. Postado em 25 Fev 2011. Disponível em: http://www.riourucuia.com.br/documentos/Historia.pdf. Acesso em: 20 jun. 2017.

MINISTÉRIO DO MEIO AMBIENTE - MMA, 2004. Disponível em: http://www.mma.gov.br/sitio/index.php?ido=conteudo.monta\&idEstrutura=72\&idMenu=2.

Acesso em: 18 jun. 2017.

MOURÃO, N. M. Sustentabilidade na produção artesanal com resíduos vegetais: uma aplicação prática de design sistêmico no Cerrado Mineiro. 2011. Dissertação de Mestrado em Design. Universidade do Estado de Minas Gerais, Belo Horizonte, 2011.

OLMOS, F. Populações tradicionais e a biodiversidade. Artigo postado em 02 set 2009 . Disponível em: http://www.oeco.com.br/fabio-olmos/21088-populacoestradicionais-e-abiodiversidade. Acesso em: 20 jul. 2017.

PREFEITURA MUNICIPAL DE CHAPADA GAÚCHA/MG. Disponível em: http://www.chapadagaucha.mg.gov.br/258/Noticias/IxEncontroDosPovosDoGrandeSertaoV eredasDe09A11De_102385/. Acesso em: 18 jun. 2017.

SALGADO, C. L. A prática educativa e o desenvolvimento territorial: um estudo de caso no município de Chapada Gaúcha, MG. Unb: Brasília, 2010. (Dissertação de mestrado)

SANTANA, L. R.; OLIVEIRA, Tiago Pires. $O$ patrimônio cultural imaterial das populações tradicionais e sua tutela pelo direito ambiental. Anais do $9^{\circ}$ Congresso Brasileiro de Direito Ambiental, São Paulo: Antônio Herman Benjamin, 2005.

SILVA, L. C.; PEREIRA, A. M. Considerações sobre a urbanização no Cerrado Mineiro. I Colóquio das cidades e regiões: Dinâmica dos espaços urbanos e rurais, 2010. Unimontes: Montes Claros. Disponível em: www.unimontes.br/arquivos/novidades/2010/Anais_do_I.../CO.pdf. Acesso em: 30 mai. 2017.

SOUZA, F. A. A. A cultura tradicional do sertanejo e seu deslocamento para implantação do Parque Grande Sertão Veredas. Viçosa: UFV, 2006.

TÖNNIES, F.. (1987). Comunidade e sociedade: textos selecionados. In: MIRANDA, Orlando (Org.). Para ler Ferdinand Tönnies. São Paulo: Edusp, 1995. p. 231-352. 
UNIÃO INTERNACIONAL PELA CONSERVAÇÃO DA NATUREZA - IUCN. Disponível em: https://www.iucn.org/node/14404. Acesso em: 28 jun. 2017.

YIN, R. K. Estudo de caso: planejamento e métodos. $3^{\text {a }}$ ed. Porto Alegre: Bookman, 2005. 